\title{
Optimal Policy and Network Effects for the Deployment of Zero Emission Vehicles *
}

\section{This Preliminary Draft April 2018}

\author{
Guy Meunier ${ }^{a, b \dagger}$ Jean-Pierre Ponssard ${ }^{b, c}$
}

${ }^{a}$ INRA-UR1303 ALISS

${ }^{b}$ CREST - Ecole Polytechnique

${ }^{c}$ CNRS

${ }^{*}$ The authors would like to thank Michel Moreaux, Guillaume de Smedt, Fabien Prieur and Floriane Dieuleveut for their comments. Financial support from the Chair Energy et Prosperity at Fondation du Risque and from ANR/Investissements d'avenir (ANR-11-IDEX-0003-02) is gratefully acknowledged.

${ }^{\dagger}$ Corresponding author, e_mail: guy.meunier@inra.fr 


\section{Executive summary}

Emissions from land transport are a major source of greenhouse gas emissions (approximately $24 \%$ for the EU28). Urban pollution, in particular particulate matter (PM2.5) and ground level ozone, is causing 3 millions of premature deaths yearly. Battery and fuel cell electric vehicles (BEV and FCEV respectively) are thought to be attractive technologies to face these societal challenges. However, with the exception of Norway, the current market shares remain quite low for BEV and anecdotal for FCEV. The common explanations for this slow penetration are: the high price of electric cars, their limited range and the lack of filling infrastructure. The last two issues explains "range anxiety": the fear of running out of power.

We formalize the interaction between three major factors that drive the deployment of zero emission vehicles: indirect network effects for adopters (i.e. range anxiety), scale effects to reduce the cost at the production stage (learning-by-doing and spillovers), and the degree of competition in the market with its influence on the price of cars. These three factors are embedded into a static partial equilibrium model. Consumers derive utility from transportation and incur a utility loss from filling. Consumers pay for the car, the fuel but not for the stations themselves. The benefit derived from the size of the network of stations is unpriced. Each firm production cost depends on the aggregate car production through a scale effect. Car producers compete à la Cournot. Filling stations are price-takers on the fuel retail market, and each has a limited capacity (convex cost).

Our analysis explores various stages of deployment: take-off, building-up and expansion stages. From an economic standpoint our three factors may be interpreted as three externalities, or market failures, which may induce a distorsion between the market equilibirum and the social optimum. The relative magnitude of the distorsion will depend on the stage of deployment. At the take-off stage we may have a degenerate market equilibrium with no cars while the social optimum would imply a positive deployment. At the building-up stage there may be three market equilibria, the equilibrium with the largest deployment generating the highest welfare. The intermediate equilibrium is a tipping point. Indeed if the initial market position lies below the intermediate equilibrium it will converge to the lowest one while if it lies higher it will converge to the preferred equilibrium. At the expansion stage the 
distorsion is reduced and eventually disappears as the significance of externalities decrease with the size of the market. For each possible stage we investigate the joint optimal subsidies for infrastructure and car adopters (i.e. price rebates) so that the social optimum can be implemented as a market equilibrium, i.e decentralized through market forces.

Our results are illustrated with data on hydrogen cars (FCEV) based on Creti et al. (2018). According to our calibration, a subsidy of approximately $80 \%$ of the fixed capital cost of a hydrogen retailing station and a rebate of approximately $10 \%$ on the listed price of cars would be necessary at the take-off stage. If the market is stagnating with a low deployment, strong public-private initiatives involving temporary demonstration projects, may be needed to pass the tipping point. The total level of subsidies would significantly increase as the deployment builds-up to eventually vanish as market failures disappear. A side result of our analysis shows that if the regulator can only subsidize vehicles or infrastructure, but not both, the return in welfare terms and in the size of the car park is higher with the former policy instrument.

Our static model has the advantage of providing analytical solutions and explicit guidelines for policies. It provides a framework which fits rather well with the observed deployment of electric vehicles in Norway as extensively discussed in (Figenbaum, 2016). However it should be considered as a first step to build more elaborate analytical models, in particular dynamic ones. Indeed a dynamic model would be more appropriate to analyze the efficiency of the many instruments that have been put in place by authorities in different megalopolis in reaction to the growing concern with urban pollution. Ideally the interaction

between the various technologies such as BEV and FCEV with these policies should also be introduced. This is the direction followed by Harrison and Thiel (2017). We think that our model provides a useful complement for the interpretation of such large complex models.

Keywords: E-mobility; network effects; joint incentives for infrastructure and car rebates 


\begin{abstract}
We analyze the impact of indirect network effects in the deployment of zero emission vehicles in a static partial equilibrium model. In most theoretical analysis direct and indirect effects are conflated, and relatively few authors have explicitly considered indirect network effects. We also introduce the market power of vehicle producers and scale effects in the production function. The model exhibits a multiplicity of local social extrema and of market equilibria, suggesting a possibility of lock-in. The optimal set of subsidies is derived so that the Pareto dominating market equilibrium would coincide with the social optimum. This framework is applied to the case of the fuel cell electric (hydrogen) vehicles.
\end{abstract}

JEL Classification: Q55, Q42, C61

Keywords: E-mobility; network effects; joint incentives for infrastructure and car rebates 


\section{Introduction}

Emissions from land transport are a major source of greenhouse gas emissions (approximately $24 \%$ for the EU28). ${ }^{1}$ A large fraction of these emissions comes from passenger cars and trucks which heavily rely on fossil fuels. The number of light duty vehicles may double until 2050 (IEA, 2013). Urban pollution, in particular particulate matter (PM2.5) and ground level ozone, is causing 3 millions of premature deaths yearly (OECD, 2014). Battery and fuel cell electric vehicles (BEV and FCEV respectively) are thought to be attractive technologies to face these challenges. However, with the exception of Norway, the current market shares remain quite low for $\mathrm{BEV}$ and anecdotal for $\mathrm{FCEV}$, in spite of substantial incentives (Lévay et al., 2017; Bjerkan et al., 2016; IEA, 2017).

The main reasons ordinarily advanced to explain such a low rate of penetration are: the high price of electric vehicles and the range anxiety due to the absence of an adequate infrastructure of refilling stations both for BEV (fast charging stations) and FCEV. While most of the literature focuses on the role of purchasing rebates (Diamond, 2009; Brand et al., 2013; Hidrue et al., 2011), only a few authors have discussed the impact of encouraging an adequate infrastructure (Meyer and Winebrake, 2009; Harrison and Thiel, 2017). Providers of infrastructure will not invest without a substantial EV market, and EV consumers will not buy without the existence of an efficient infrastructure.

The objective of this paper is to formalize the critical role of infrastructure in this economic setting. We consider a static partial equilibrium model. Car producers compete à la Cournot. Each firm production cost depends on the aggregate car production through a scale effect. Filling stations are price-takers on the fuel retail market. Consumers derive utility from transportation and incur a utility loss from filling related to the cost of searching and reaching a station. The benefit derived from the size of the network of stations is unpriced. Consumers pay for the car, the fuel but not for the stations themselves.

We prove the existence of both multiple welfare local extrema (Proposition 1) and multiple market equilibria (Proposition 2), which introduces the possibility of lock-in to be

\footnotetext{
${ }^{1}$ See http://ec.europa.eu/eurostat/statistics-explained/index.php/Climate_change__driving_forces
} 
discussed in section 4.1. Both features are related to consumer cost to search and reach a filling station, which is decreasing with the density of the network of filling stations, and introduce a non-convexity. Furthermore, even the "best" (Pareto dominating) market equilibrium is inefficient because of market failures. In Proposition 3 the relative welfare loss between the Pareto dominating market equilibrium and the social optimum is proved to decrease with the willingness to pay for zero emission vehicles. Proposition 4 gives the optimal couple of subsidies (i.e. car rebates and subsidies for the investment cost of refilling stations) so as to achieve the social optimal through market forces. We also consider the case in which there is an integrated monopoly providing simultaneously cars and stations (Proposition 5). The benefit of integrating the network externality has to be balanced with the increased market power. Finally we analyze the case in which the regulator can only subsidize vehicles (Proposition 6) or infrastructure (Proposition 7). This will allow for an analysis of the return of such subsidies both in welfare terms and in the expansion of the car park.

To our knowledge Greaker and Heggedal (2010) is the only existing theoretical analysis of the interaction between car production and filling stations deployment. Greaker and Heggedal (2010) assume a perfectly competitive market for car manufacturers while refilling stations imperfectly compete on a circle à la Salop. There are some important differences between our model and theirs. While their model leads to excessive entry of filling stations ours leads to less than efficient entry, which is more in line with observations and intuition. In both models the market interaction generates multiple equilibria and the possibility of lock-in. However they do not analyze optimal subsidies while we do. Our model allows for the analysis of the respective role of imperfect competition, scale and (indirect) network effects. We also explore an alternative market structure such as an integrated monopoly.

Network effects describe situations in which the utility of a user is affected by the number of users. Indirect network effects occur via a complementary good (e.g. stations) the supply of which increases with the number of users of the primary good (e.g. cars). ${ }^{2}$ Shy (2011)

\footnotetext{
${ }^{2}$ The interaction between hardware and software is a frequent example of a sector with indirect network effects, the analogy with the transportation car sector would be that a car corresponds to a hardware and a filing station to a software.
} 
provides a brief survey of the literature notably in industrial organization. In most analysis direct and indirect effects are conflated, and relatively few authors have explicitly considered indirect network effects (e.g. Chou and Shy, 1990; Clements, 2004; Church et al., 2008). The same situation holds in environmental economics (e.g. Sartzetakis and Tsigaris, 2005; Brécard, 2013; Greaker and Midttømme, 2016; Nyborg et al., 2016). ${ }^{3}$

Whether indirect network effects are associated with a market failure and call for regulation is arguable (Liebowitz and Margolis, 1995), after all, plenty of complementary goods are provided by the market without regulatory supervision. In our framework filling stations are under provided because of an unpriced benefit derived by consumers from stations: the reduction of utility costs from searching and reaching a filling station. ${ }^{4}$ We show that regulation is critical at the take-off stage.

We apply our model to the case of FCEV deployment, based on Creti et al. (2018). As an introduction to this section some general background on the deployment stages of new technologies is provided based on Geels (2002), with a review of the historical deployment of BEV in Norway (Figenbaum (2016)). This provides a useful perspective for discussing the insights of our model. We derive the optimal set of subsidies and show that a very substantial subsidy on the investment cost of infrastructure (up to 80 during the take-off stage $\%$ ) and a $10 \%$ rebate on the retail price of vehicles would be adequate for market forces to achieve the social optimum. Interestingly the discussion suggests that there would be large benefits of combining local analysis (i.e. the right level for analyzing infrastructure and network externalities) with global analysis (i.e. the right level for analyzing scale effects and competition for car manufacturers ).

The paper is organized as follows: In the following section the model is introduced and the social optimum studied. In section 3 the market equilibria are derived and compared to the social optimum. The optimal subsidies to achieve the social optimum through market forces are identified. In section 4, we discuss second best approaches: the case of integrated

\footnotetext{
${ }^{3}$ There is also a vast literature on technical lock-in, notably related to network effects or learning-by-doing spillovers Arthur (1989) is a seminal contribution (see also Kline, 2001).

${ }^{4}$ Interestingly, while Church et al. (2008) claim that "increasing returns to scale in the production of software" (stations in our case) is a necessary conditions for indirect network effects, it is not the case in our model.
} 
monopoly or the case in which only subsidies on cars or on infrastructure can be used. The model is applied to a proposed scenario for FCEV in Germany in section 5. Section 6 concludes.

\section{The model and the social optimum}

\subsection{Framework}

We consider two complementary goods: cars and filling stations. The total quantity of cars is $X$ and the number of filling stations $K$. The distance traveled per car, and hence the quantity of fuel, are fixed and units are normalized so that the total quantity of fuel consumed is $X$.

The gross consumer surplus from consuming $X$ cars with $K$ filling stations is $S(X, K)=$ $s(X)-r(K) X$. The term $s(X)$ is the utility from transportation and car ownership, and the term $r(K)$ is the utility loss per car associated with filling, the cost to search and reach a filling station. This term is related to the fear of running out of power while driving so that $r(K)$ refers to the phenomenon known as range anxiety. It is positive, decreasing and concave with $r(0)=+\infty$ and $r^{\prime}(0)=-\infty$. We will assume that $s(X)$ is quadratic and $r(K)$ inversely proportional to $K$ :

$$
s(X)=\left(a-\frac{b}{2} X\right) X \text { and } r(K)=\frac{\beta}{K}
$$

in which $a, b, \beta>0$. The parameter $\beta>0$ will be called the range anxiety factor. If there are less than $\beta / a$ stations even free cars cannot generate a positive gross surplus. ${ }^{5}$

The parameters $a$ and $b$ generate the demand function. The paremeter $a$ will be referred to as the willingness to pay for zero emissions vehicles. It increases with the social cost of carbon and the ecological attitude of consumers. The parameter $b$ is related to the elasticity of the demand function and the size of the market.

\footnotetext{
${ }^{5}$ It would be more satisfying to take $S(X, K)=\max \{s(X)-r(K) X, 0\}$ to ensure that gross surplus is always positive, however it would considerably increases the complexity of the analysis without any benefits since, at the optimum or equilibrium the gross surplus is never negative.
} 
The total cost to produce $X$ vehicles is $C_{V}(X) . X$. The unit production cost is decreasing with the total quantity produced. The following specification is used: $C_{V}(X)=\max \left\{c_{0}-\right.$ $g X, 0\}$, in which $g<b / 2$ to ensure concavity of welfare with respect to $X{ }^{6}$ The parameter $g$ will be refereed to as the scale factor.

Operating a filling station incurs a fixed cost $f$, and a convex cost $C_{F}(x)$ to provide $x$ units of fuel, with $C_{F}(0)=0, C_{F}^{\prime}(x)>0$ and $C_{F}^{\prime \prime}(x)>0$. The strict convexity captures the capacity constraint of a filling station. A quadratic cost function is used $C_{F}(x)=c_{F} x^{2} / 2$. At the optimum and market equilibrium, each station provides the same quantity of fuel $x=X / K$.

Total welfare is then

$$
W(X, K)=S(X, K)-C_{V}(X) X-C_{F}(X / K) K-f K
$$

There are two interacting markets: the market for cars and the retail market for fuel, or market for "filling". We do not model upstream fuel production and distribution to filling stations. The price of a vehicle is $p_{V}$ and the retail price of fuel is $p_{F}$. Capital letters $P_{V}$ and $P_{F}$ are used for price functions. Total welfare can then be decomposed as the sum of net consumer surplus, car producers profit, and the profits of filling stations operators.

$$
W(X, K)=\left[S(X, K)-\left(p_{V}+p_{F}\right) X\right]+\left[p_{V}-C_{V}(X)\right] X+\left[p_{F} \frac{X}{K}-C_{F}\left(\frac{X}{K}\right)-f\right] K
$$

The minimum efficient scale of a station denoted $x_{m}$ equalizes average and marginal cost: $\left(f+C_{F}\left(x_{m}\right)\right) / x_{m}=C_{F}^{\prime}\left(x_{m}\right)$. The associated average cost is denoted $\bar{C}_{F}$. With our specification they are equal to:

$$
x_{m}=\sqrt{\frac{2 f}{c_{F}}} \text { and } \bar{C}_{F}=\sqrt{2 f c_{F}}
$$

In the following it is assumed that $g$, the scale factor, is sufficiently small so that at both the optimum and all market equilibria scale is not exhausted, that is $X<c_{0} / g$. Altogether the parameters safisfy:

\section{Assumption}

$$
0<\frac{a-c_{0}-\bar{C}_{F}}{b-2 g}<\frac{c_{0}}{g}
$$

\footnotetext{
${ }^{6}$ This formulation in a static model captures scale effects as well as learning-by-doing and spillovers from one firm to the other. Strategic aspects associated to these phenomena are neglected.
} 


\subsection{Social optimum}

Let us first look at the social optimum. The welfare function described by equation (2) is not concave, there might be several critical points, and the first order conditions are not sufficient to ensure optimality. ${ }^{7}$ Denote the optimal quantities of cars and stations $X^{*}$ and $K^{*} \cdot 8$

There is always a local maximum at $(X, K)=(0,0)$ : if there is no car produced it is not worth investing in filling stations and vice-versa. If both $X^{*}$ and $K^{*}$ are positive they solve the following first order conditions:

$$
\begin{array}{r}
s^{\prime}(X)-r(K)=C_{V}(X)+C_{V}^{\prime}(X) X+C_{F}^{\prime}(X / K) \\
-r^{\prime}(K) X+\left[C_{F}^{\prime}\left(\frac{X}{K}\right) \frac{X}{K}-C_{F}\left(\frac{X}{K}\right)\right]=f
\end{array}
$$

The marginal consumer surplus from an additional vehicle should be equalized with the marginal cost to produce and fill the vehicle. The marginal production cost encompasses the scale effect $C_{V}^{\prime}(X)$. The marginal filling cost, $C_{F}^{\prime}$ depends upon the number of stations. To build an additional station costs $f$ but reduces the range anxiety $\left(-r^{\prime}(K)>0\right)$ and the cost of filling (bracketed term).

From these first order conditions, we can define two functions $X^{0}(K)$ and $K^{0}(X)$ as the unique solution of (5) and (6) respectively. The optimum couple then solves $X^{*}=X^{0}\left(K^{*}\right)$ and $K^{*}=K^{0}\left(X^{*}\right)$, and each solution of this couple is a critical point.

With our specification, equation (6) gives the optimal quantity of stations for a given quantity of cars:

$$
K^{0}(X)=X\left[\frac{1}{f}\left(\frac{\beta}{X}+\frac{c_{F}}{2}\right)\right]^{1 / 2}=\frac{X}{x_{m}}\left[1+\frac{2 \beta}{c_{F} X}\right]^{1 / 2} .
$$

Concerning the optimal quantity of cars as a function of $K$ : it is null for small $K$, and non-negative for large $K$. Its explicit expression depends whether it is lower, equal or larger

\footnotetext{
${ }^{7}$ More precisely the welfare function $W(X, K)$ is concave with respect to $X$ and with respect to $K$ $\left(W_{X X} \leq 0\right.$ and $\left.W_{K K} \leq 0\right)$ but not with respect to $(X, K)$ because of the cross derivative $W_{X K}=(\beta-$ $\left.c_{F} X\right) / K^{2}$ which is larger than $\sqrt{W_{X X} \times W_{K K}}$ for small $K$. This feature is necessary to have a multiplicity of critical points.

${ }^{8}$ In case of multiplicity $\left(X^{*}, K^{*}\right)$ is the maximizing couple with the largest $X$.
} 
than $c_{0} / g$. For small enough $K, X^{0}$ is lower than $c_{0} / g$ given by :

$$
X^{0}(K)=\max \left\{\frac{a-c_{0}-\beta / K}{b-2 g+c_{F} / K}, 0\right\} .
$$

For large $\beta,(0,0)$ is the only solution of the system of equations. Otherwise, in cases of interest, there are three solutions to this system of equations $(0,0)$ and two non-negative critical points $\left(X_{-}^{*}, K_{-}^{*}\right)$ and $\left(X_{+}^{*}, K_{+}^{*}\right)$ with $X_{-}^{*}<X_{+}^{*}$, the first being a saddle point and the second a local maximum (see Appendix A). The social optimum is then either $(0,0)$ or $\left(X_{+}^{*}, K_{+}^{*}\right)$. As a benchmark, it is worth considering the case without range anxiety: $\beta=0$.

Lemma 1 If consumers do not experience range anxiety that is, $\beta=0$, the optimal quantity of cars is positive (thanks to assumption A1) and each station operates at the minimum efficient scale:

$$
X^{*}=\frac{a-c_{0}-\bar{C}_{F}}{b-2 g}>0 \text { and } K^{*}=\frac{X^{*}}{x_{m}}
$$

In that case filling stations are equivalent to fuel production plants, and should operate at the minimum efficient scale. The optimal number of stations is then simply the quantity of cars divided by the minimum efficient scale. The corresponding average cost of filling should be incorporated as a linear function of the number of cars. This situation may be seen as a completed deployment in which $K$ is sufficiently large so that range anxiety disappears.

Proposition 1 As $\beta$ increases the social optimum jumps from $\left(X_{+}^{*}, K_{+}^{*}\right)$ to $(0,0)$.

For small $\beta,\left(X_{+}^{*}, K_{+}^{*}\right)$ is the optimum, and each station operates at a scale lower than the minimum efficient scale: $X^{*} / K^{*}<x_{m}$, and a small increase of the range anxiety factor $\beta$ induces a reduction of the optimal quantity of vehicles, and an increase of the quantity of stations per vehicle.

The proof is in appendix A.1. This is illustrated Figure 1. On Figure 1(a) welfare as a function of $X$ is depicted, with the optimal quantity of filling stations $K^{0}(X)$. Different values of $\beta$ are considered. ${ }^{9}$ For $\beta=0$, welfare is concave and there is a unique extremum

\footnotetext{
${ }^{9}$ The function depicted is $W\left(X, K^{0}(X)\right)=\max _{K} W(X, K)$, it is not concave for $\beta>0$, even though the function $W(X, K)$ is concave with respect to $X$ for any given $K$.
} 
which is a global maximum (Lemma 1 ). For $\beta=5$ or 12 , there are three local extrema, a minimum at $X_{-}^{*}$ (empty circle) and two maxima (full circle): 0 and $X_{+}^{*}$. For $\beta=5$, the interior maximum is the global optimum and for $\beta=12$ the optimum is $(0,0)$.

On Figure 1(b), the two functions $K^{0}(X)$ and $X^{0}(K)$ are plotted together with iso-welfare curves. The Figure shows that the intersects of $K^{0}(X)$ and $X^{0}(K)$ correspond to the three extrema of the function $W\left(X, K^{0}(X)\right)$. Furthermore, looking at the iso-welfare curve shows that the minimum corresponds to a saddle point of $W(X, K)$.

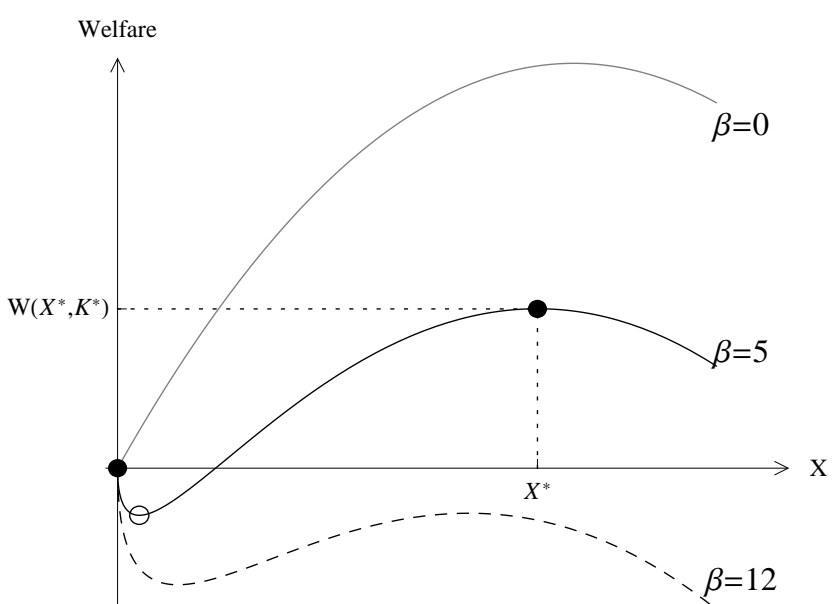

(a) Welfare with respect to $X$

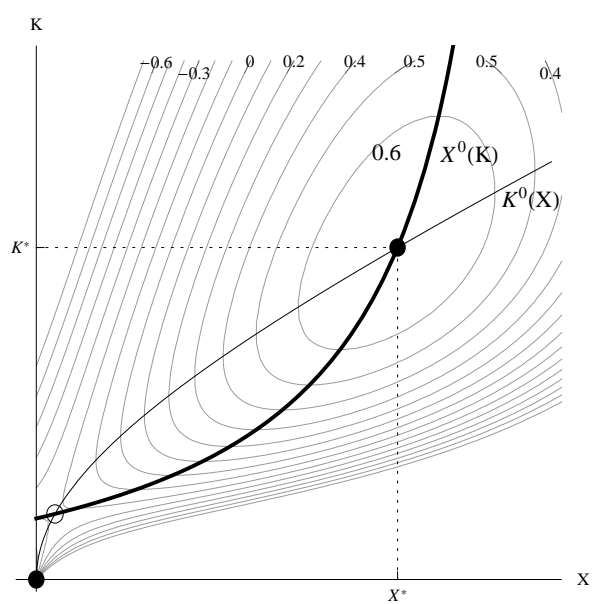

(b) Determination of the optimal $X$ and $K$ for $\beta=5$. The gray lines are iso-welfare curves.

Figure 1: Optimal welfare as a function of the number of cars for $a=3.5, c_{0}=1, g=0.1$, $b=1, f=0.1, c_{F}=2$ and three values of $\beta$ : 0 (gray lines), 3 (black plain lines), 12 (dashed lines).

Figure 1 illustrates the discountinuous nature of the optimal solution with respect to parameters, due to the non-concavity of the welfare function. The figure illustrates the impact of a change of $\beta$, but other parameters can also induce a discontinuous shift of the optimum. A continuous increase of the willingness to pay a triggers a jump in the optimal policy. The global optimum cannot be determined via first order conditions and requires the comparison of total welfare at the two local maxima.

The multiplicity of extrema and discontinuity of the optimal solution with respect to parameters are both due to range anxiety $\beta X / K$. The following corollary shows that these 
issues are particularly acute when $X$ is small, and negligible for large $X$. It is at the initial development stage of the new technology that the cost of the complementary network is problematic because the number of stations per car is large. If the willingness to pay for cars is large the costs of filling, which includes both the utility loss and the cost of stations, becomes negligible and the situation is similar to a situation with $\beta=0$.

Corollary 1 The range anxiety term $\beta X^{*} / K^{*}$ becomes negligible as the willingness to pay "a" increases.

- The number of stations per car decreases with respect to a. The size of stations increases and converges toward $x_{m}$, the cost of stations per car converges toward $\bar{C}_{F}$.

- The total utility loss from filling is bounded and converges toward $\beta x_{m}$, the range anxiety per car $\left(\beta / K^{*}\right)$ decreases toward zero.

- The welfare loss compared to a situation with $\beta=0$ converges towards 0:

$$
\frac{\left(a-\bar{C}_{F}\right)^{2} / 2 b-W\left(X^{*}, K^{*}\right)}{\left(a-\bar{C}_{F}\right)^{2} / 2 b} \underset{a \rightarrow+\infty}{\longrightarrow} 0
$$

Proof in Appendix A.2. When the parameter $a$ is increased towards infinity, assumption A1 is no longer satisfied and scale effects are exhausted, the situation corresponds to $c_{0}=$ $g=0$.

\section{Market equilibrium}

Car producers compete à la Cournot, with a fixed number of competitors. Filling stations are price takers, and entry is free. A market equilibrium is then a couple of quantities of cars $X$ and stations $K$, at the intersect of two reaction functions $X^{r}(K)$ and $K^{r}(X)$. The reaction function $X^{r}(K)$ is the agregate production in which each firm maximizes its profit for a given $K$ assuming that each other firm plays its equilibrium quantity. The reaction function $K^{r}(X)$ is the total number of stations for a given $X$ assuming that the demand for fuel is equally divided among operators and that the total number of operators is such that the profit of an operator is null. 


\subsection{Filling station}

The market for refilling works as a "textbook" perfectly competitive market. For a given price of fuel $p_{F}$, a station supplies the quantity $x$ that equalizes price and marginal cost. Its profit is then $p_{F} x-C_{F}(x)-f$, and entry is profitable as long as $p_{F}>\bar{C}_{F}$.

For a given quantity of cars and stations, the fuel price ensures that a quantity $X$ is supplied: $p_{F}=C_{F}^{\prime}(X / K)=c_{F} X / K$. At the free-entry equilibrium, the price of fuel is equal to the average cost $\bar{C}_{F}$ and each station operates at the minimun efficient scale:

$$
K^{r}(X)=\frac{X}{x_{m}} .
$$

Compared to $K^{0}(X)$, given by equation (7), there are less stations per car because filling station owners do not internalize the effect of stations on range anxiety.

It is worth stressing the difference between the present model and the one developped by Greaker and Heggedal (2010). They consider that stations have no capacity constraint $\left(c_{F}=0\right)$, and model the price fixing process as a price competition along a circle à la Salop (1979) which leads to $p_{F}(K)=4 \beta / K$. Such a model leads to the counter-intuitive result of excessive entry of filling stations. This approach is common in the theoretical literature on indirect network effects (e.g. Clements, 2004; Church et al., 2008) but it is not adequate for e-mobility.

Indeed, without capacity constraint at the station level $\left(c_{F}=0\right)$, there is no competitive equilibrium because of scale economies. Capacity constraints have both a methodological and empirical appeal. Methodologically, it allows to have a clear competitive benchmark corresponding to the optimum, and identify the externality responsible for the suboptimality of the number of stations. From an empirical standpoint, in the study by McKinsey \& Company (2010) on the deployment of hydrogen, the capacity of stations is bounded at 1 $000 \mathrm{~kg} \mathrm{H} /$ day. 


\subsection{Car production}

Car producers compete à la Cournot, taking as fixed both the quantity of stations $K$ and the fuel retail price $p_{F} \cdot{ }^{10}$ Their anticipation of the fuel retail price is fulfilled at the equilibrium so that $p_{F}=c_{F} X^{r}(K) / K$.

The inverse demand function facing these Cournot producers is:

$$
P_{V}(X, K)=\frac{\partial S}{\partial X}-p_{F}=a-\frac{\beta}{K}-b X-p_{F}
$$

The profit of a car producer producing $X_{i}$ and facing a production $X_{-i}=X-X_{i}$ by the others is

$$
\pi_{V}\left(X_{i}, X_{-i}, K\right)=\left[P_{V}\left(X_{i}+X_{-i}, K\right)-C_{V}\left(X_{i}+X_{-i}\right)\right] X_{i}
$$

If there are $m$ symmetric Cournot competitors, the equilibrium quantity $X^{r}(K)$ is uniquely defined and is either 0 if $P_{V}(0, K)<C_{V}(0)$ or the solution of

$$
P_{V}(X, K)-C_{V}(X)+\left[\frac{\partial P_{V}}{\partial X}-C_{V}^{\prime}\right] \frac{X}{m}=0 .
$$

Lemma 2 For a given quantity of stations $K$, there is a unique equilibrium total quantity of $\operatorname{cars} X^{r}(K)$.

- If $K<\beta /\left(a-c_{0}\right)$, no vehicles are produced: $X^{r}(K)=0$;

- If $K>\beta /\left(a-c_{0}\right)$ then

$$
X^{r}(K)=\frac{m}{m+1} \frac{1}{b-g}\left[a-c_{0}-\frac{\beta}{K}-p_{F}\right]=\frac{a-c_{0}-\beta / K}{\frac{m+1}{m}(b-g)+c_{F} / K}
$$

See Appendix B.

For any $K$ there is a discrepancy between the optimal $X$ and the oligopoly reaction function related to market power and scale effects. Comparing equation (8) and equation (14) it is easily seen that the difference between $X^{r}(K)$ and $X^{0}(K)$ is decreasing with $m$ and increasing with $g$, which is consistent with intuition.

\footnotetext{
${ }^{10}$ Another possibility is to assume that car producers anticipate the influence of the number of vehicles on the equilibrium price of fuel $p_{F}=c_{F} X / K$, exercising their market power as an oligopsony on the fuel retail market. It would slightly complicate the analysis without adding any relevant insights.
} 


\subsection{The market equilibria}

Combining both reaction functions we get the following proposition.

Proposition 2 There is a unique equilibrium at $X=0$ and $K=0$ if and only if

$$
\beta>\frac{1}{4} \frac{m}{m+1} \frac{\left(a-c_{0}-\bar{C}_{F}\right)^{2}}{x_{m}(b-g)}
$$

Otherwise, there are three equilibria each characterized by a quantity of cars $X \in\left\{0, X_{-}^{E}, X_{+}^{E}\right\}$. There is one stable equilibrium at $X=0$ and $K=0$ and another stable equilibrium with $X=X_{+}^{E}>0$, and an unstable equilibrium in between the two stable ones: $0<X_{-}^{E}<X_{+}^{E}$.

$$
X_{ \pm}^{E}=\frac{m}{m+1} \frac{a-c_{0}-\bar{C}_{F}}{b-g}\left\{\frac{1}{2} \pm \frac{1}{2} \sqrt{1-4 \beta \frac{m+1}{m} \frac{(b-g) x_{m}}{\left(a-c_{0}-\bar{C}_{F}\right)^{2}}}\right\} \text { and } K_{ \pm}^{E}=\frac{X_{ \pm}^{E}}{x_{m}}
$$

The proof is in Appendix B.2. Stability is defined referring to the aggregate reaction functions $X^{r}(K)$ and $K^{r}(X)$ so that any tâtonnement process starting close to the equilibrium would converge to the equilibrium, formally it is so if the slope of $K^{r}(K)$ is lower than the inverse of the slope of $X^{r}(K)$.

Proposition 2 is illustrated on Figure 2, the two reaction functions are depicted and the equilibria are at their intersects. The filled circle corresponds to the unstable low equilibrium, the empty circles to the two stable equilibria. The unstability of the $X_{-}^{E}$ equilibrium is illustrated by the arrows: a few more filling stations would trigger a tâtonnement towards the stable large $X_{+}^{E}$ equilibrium while with a few less stations it would trigger a tâtonnement towards the equilibrium with no car and no station. The unstable $X_{-}^{E}$ equilibrium can be

interpreted as a "tipping point". The dotted lines described the social optimum, as can be seen both the optimal quantity of cars and stations are larger than the equilibrium ones. 


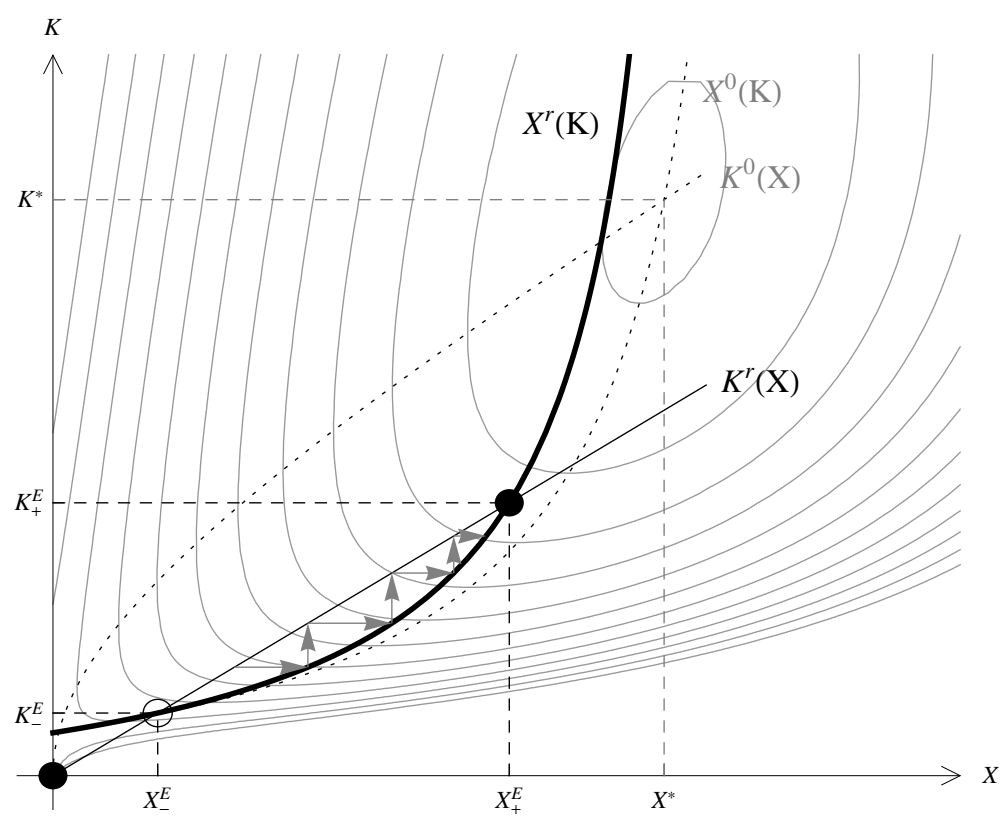

Figure 2: Market reaction functions, equilibria and iso-welfare for $a=5, b=1, c=1$, $g=0.01, m=10, \beta=5, f=0.1, c_{F}=2$

The differences between the market reaction functions and the optimal functions is linked to the three market failures at play: market power, scale effects and network effects. The modeling approach adopted ensures that all these inefficiencies could be "switched-off" by setting $m=+\infty$, and $g=\beta=0$, so that a competitive benchmark exists. This competitive benchmark decentralizes the corresponding optimum and no regulation is needed in that case.

Corollary 2 For $\beta=0, g=0$ and $m=+\infty$, there is a unique stable market equilibrium which corresponds to the optimum allocation $\left(X^{*}, K^{*}\right)$.

\section{Optimal policy}

The regulator faces two issues: a possible lock-in at a Pareto dominated equilibrium, and the suboptimality of car and station quantities even at the Pareto equilibrium. Policies to address these issues will be discussed successively. 


\subsection{Lock-in}

A lock-in situation may occur if there are several market equilibria, and the prevailing equilibrium is not the best one. In the present model, it is straightforward to compare market equilibria when several co-exist: The equilibrium with the largest quantities of stations $\left(K_{+}^{E}\right)$ Pareto dominates the other two. Both consumer surplus and car producer profits are increasing with respect to the quantity of stations, and the profit of filling stations being null, the following corollary holds.

Corollary 3 If there are several market equilibria, welfare, consumer surplus and vehicle producers profit are larger at $\left(X_{+}^{E}, K_{+}^{E}\right)$ the stable market equilibrium with the largest quantity of vehicles.

It is therefore recommended to push the market towards the large stable equilibrium. To do so, the regulator can invest (directly or indirectly via a call for tenders) in $K_{-}^{E}$ stations. It would ensure that only the large $\left(X_{+}^{E}, K_{+}^{E}\right)$, Pareto dominating, equilibrium prevails. This may be interpreted as the need for an involvement of the state in the demonstration projects (see section 5.1 for some evidence in line with this recommendation).

The parallel between the multiplicity of local welfare critical points and market equilibria is apparent from Figure 2. The welfare saddle point is more or less associated with an unstable market equilibrium and a welfare local maximum with a stable one. The optimal policy could be decomposed in two steps: First, cross the tipping point, so that $(0,0)$ is no longer a stable equilibrium and a unique equilibrium exists. Second, the regulator should set subsidies to realign this market equilibrium with the optimum. Graphically, on Figure 2, each step is associated to a climb on the welfare mountain. Formally, optimal welfare could be written as:

$$
W\left(X^{*}, K^{*}\right)=\underbrace{\left[W\left(X_{+}^{E}, K_{+}^{E}\right)-W(0,0)\right]}_{\text {First step gains }}+\underbrace{\left[W\left(X^{*}, K^{*}\right)-W\left(X_{+}^{E}, K_{+}^{E}\right)\right]}_{\text {Second step gains }}
$$

Before considering the optimal couple of subsidies needed for the second step, it is worth analyzing the welfare gains associated with each of these two steps. It is not feasible to do so analytically, but a comparative static exercise on consumer willingness to pay could 
be performed. As the demand for cars increases two of the three sources of inefficiencies vanish: scale effects are fully exploited and range anxiety becomes negligible. The situation is then comparable with a standard Cournot oligopoly in which the relative loss is inversely proportional to the number of competitors (cf Corchón, 2008, for a generalization).

Proposition 3 The relative welfare loss between the equilibrium $\left(X_{+}^{E}, K_{+}^{E}\right)$ and the optimum is eventually decreasing with respect to consumers willingness-to-pay "a" and converges toward

$$
\frac{W\left(X^{*}, K^{*}\right)-W\left(X_{+}^{E}, K_{+}^{E}\right)}{W\left(X^{*}, K^{*}\right)} \underset{a \rightarrow+\infty}{\longrightarrow} \frac{1}{(m+1)^{2}}
$$

\subsection{Combined subsidies for infrastructure and vehicles}

Suppose the market would settle at $\left(X_{+}^{E}, K_{+}^{E}\right)$ thanks to initial demonstration projects, the regulator can use subsidies to align the market reaction functions and implement the social optimum.

Introduce subsidies on filling stations (as a subsidy on the capex $f$ ) and vehicles (as a rebate on the consumer price). Denote them $s_{K}$ and $s_{V}$ respectively. The quantity of filling stations is such that

$$
\frac{c_{F}}{2} \frac{X^{2}}{K^{2}}=f-s_{K}
$$

the free-entry equilibrium price of fuel is $p_{F}\left(s_{K}\right)=\sqrt{2 c_{F}\left(f-s_{K}\right)}$, and stations operates at a lower scale than without subsidy. The profit of a car producer is

$$
\pi_{V}\left(X_{i}, X_{-i}, K\right)=\left[P_{V}\left(X_{i}+X_{-i}, K\right)+s_{V}-C_{V}\left(X_{i}+X_{-i}\right)\right] X_{i}
$$

in which $P_{V}(X, K)=a-b X-\beta / K-p_{F}$, and $p_{F}=p_{F}\left(s_{K}\right)$ at the equilibrium. The regulator can select both subsidies to realign the incentives of firms and station operators to achieve the social optimum through market forces. The following proposition is easily derived from equations 7, 8 and 14 after some manipulations.

Proposition 4 The optimum can be decentralized with a subsidy couple:

$$
\begin{aligned}
& s_{K}=\frac{\beta X^{*}}{K^{* 2}} \\
& s_{V}=(b-g) \frac{X^{*}}{m}+g X^{*}
\end{aligned}
$$


The subsidy on filling stations ensures that the return on the marginal station is equal to the marginal consumers surplus from stations. The missing revenue from stations comes from range anxiety. The subsidy on vehicles is the sum of two terms, each one corresponding to a market failure: market power and scale effects.

\subsection{Integrated monopoly}

Let us consider an integrated monopoly that both produces cars and invests in filling stations. The monopoly jointly sets the prices of car and fuel. Its total profit is

$$
\begin{aligned}
\pi_{M}(X, K) & =\left[P_{V}(X, K)+s_{V}-C_{V}(X)\right] X+p_{F} X+s_{K} K-\left(c_{F}(X / K)+f\right) K \\
& =\left[(a-b X)-\frac{\beta}{K}+s_{V}-C_{V}(X)\right] X+s_{K} K-\left(C_{F}\left(\frac{X}{K}\right)+f\right) K
\end{aligned}
$$

The firm internalizes the range anxiety cost and optimally chooses the quantity of filling stations for a given $X$ and without subsidy $\left(s_{K}=0\right) .{ }^{11}$ The profit maximizing quantity of cars, if positive, solves:

$$
a-\frac{\beta}{K}+s_{V}-2 b X-\left(c_{0}-2 g\right) X=c_{F} \frac{X}{K}
$$

Compared to an oligopoly, an integrated monopoly has a greater market power but internalizes the externality from stations on the demand for cars. Both effects work in opposite directions, so that, without subsidies an integrated monopoly could be better, from a welfare perspective, than a disintegrated oligopoly. Indeed, an integrated monopoly clearly outperforms a disintegrated monopoly. Furthermore, only a subsidy on cars is necessary to implement the optimum. The derivation of the optimal subsidy follows the same route as in the preceding section.

${ }^{11}$ The optimality of the choice of $K$ by an integrated monopolist is not general but due to our specifications of $S(X, K)$ in which the marginal surplus from $K$ is linear in $X$ :

$$
\frac{\partial S}{\partial K}=X \frac{\partial^{2} S}{\partial K \partial X}\left(=X \frac{\partial P_{V}}{\partial K}\right)
$$

under a more general specification $S(X, K)=s(X)-r(K, X) X$ an integrated monopolist would still underinvest in $K$ under the plausible case of a positive cross derivative of $r$, and over-invest otherwise. 
Proposition 5 With an integrated monopoly, only a subsidy on vehicles is necessary to implement the optimum, $s_{K}=0$ and

$$
s_{V}=b X^{*}
$$

\subsection{Second best policies: subsidies either on infrastructure or on vehicles}

We consider situations in which only one subsidy is available either on vehicles or on filling stations. The regulator is only able to maximize $W\left(X, K^{r}(X)\right)$ with respect to $X$ or $W\left(X^{r}(K), K\right)$ respectively.

Consider the implementation of a subsidy on vehicles. An indirect network effect argument appears since:

$$
\begin{aligned}
\frac{\partial W}{\partial X}+\frac{\partial W}{\partial K} \frac{\partial K^{r}}{\partial X} & =\left[\frac{\partial S}{\partial X}-C_{V}-C_{V}^{\prime} X-C_{F}^{\prime}\right]+\left[\beta \frac{X}{K^{2}}+\left(C_{F}^{\prime} \frac{X}{K}-C_{F}\right)-f\right] \frac{1}{x_{m}} \\
& =\left[s^{\prime}(X)-\frac{\beta}{K}-C_{V}-C_{V}^{\prime} X-\overline{C_{F}}\right]+\beta \frac{X}{K^{2}} \frac{1}{x_{m}}
\end{aligned}
$$

Indirect network effects are encompassed in the last term. An additional car induces an increase of the quantity of stations inversely proportional to the minimum efficient scale (factor $1 / x_{m}$ ), welfare is enhanced because of the unpriced reduction of range anxiety. At the equilibrium $K=X / x_{m}$ so that this last term is simply $\beta / K$.

Proposition 6 If the regulator can only subsidize cars, the optimal subsidy on cars is

$$
s_{V}^{S B}=\beta \frac{x_{m}}{X^{S B}}+(b-g) \frac{X^{S B}}{m}+g X^{S B}
$$

in which $X^{S B}$ is larger than $X^{*}$ and equals to

$$
X^{S B}=\frac{1}{b-2 g}\left[a-c_{0}-\bar{C}_{F}\right]
$$

which is the optimal quantity of vehicles without range anxiety $\beta=0$. 
Proof in Appendix C. Surprisingly, the optimal quantity of vehicles in that case is equal to the optimal quantity of vehicles without range anxiety $(\beta=0)$ which is higher than $X^{*}$. Indeed, in equation (25) the two $\beta / K$ terms cancel each others and equation (26) follows. Alternatively, the expression of $X^{S B}$ can be obtained by noting that range anxiety is proportional to the scale of stations and this scale is fixed at $x_{m}$ when stations are not subsidize. Therefore the total utility $\operatorname{loss} \beta X / K$ is fixed and does not influence the optimal choice of $X$, but it does influence the optimal subsidy. However, since range anxiety reduces the net willingness of consumers to pay for a car, the subsidy should exactly compensate for range anxiety.

Suppose now that the regulator can only subsidize stations, the optimal second-best subsidy encompasses a term that reflect the benefits from increasing the quantity of vehicles. The influence of stations on the equilibrium quantity of vehicles occurs through two channels: the retail price of fuel and range anxiety. Only an implicit equation can be found for the optimal subsidy, and the precise expression and the comparison with the first-best quantity of stations or vehicles is out of reach.

Lemma 3 If the regulator can only subsidize filling stations, the optimal subsidy satisfies the equation:

$$
s_{K}^{S B}=\beta \frac{X}{K^{2}}+\left(\frac{b}{m}+g \frac{m-1}{m}\right) \frac{X}{K^{2}} \frac{\beta+c_{F} X}{\frac{m+1}{m}(b-g)+c_{F} / K}
$$

See Appendix C. A last noteworthy result, is a comparison of the impact of an euro spent subsidizing stations or vehicles, notably on the total quantity of vehicles. Such a comparison paves the way for a fully fledged analysis of an optimal policy with costly public funds, that is left for future research.

Lemma 4 An euro spent subsidizing filling stations has a larger impact on the quantity of vehicles than a euro spent subsidizing vehicles directly.

See Appendix C. A subsidy on vehicles directly affect the supply of vehicles, while a subsidy on stations operates indirectly via both the retail price of fuel and the range anxiety. For a small subsidy, the reduction of the retail price of fuel is equivalent to a subsidy on vehicles, and the reduction of range anxiety explains the larger effect of a subsidy on filling 
stations. Interestingly, this result is in line with the empirical analysis of Pavan et al. (2015)

of the Italian deployment of alternative fuels (Liquefied Petroleum Gas and Compressed Natural Gas).

\section{A scenario for FCEV}

\subsection{Some background information on the deployments of BEV and FCEV}

Development of new technologies typically takes many years with ups and downs, from small demonstration projects on niche markets, involving firms or collectivities, to mature achievements involving individual users. Based on the multilevel perspective proposed by Geels (2012), Figenbaum (2016) provides an illuminating exploration of the uprising of Battery Electric Vehicles (BEV) in Norway over the years 1989-2016. Of particular interest to our discussion is the period 2010-2016.

In 2010 BEV had been successfully deployed in large towns as the second car of well doing households thanks to generous subsidies (exemptions for registration and value added taxes, exemptions of charges for toll and parking, free access to bus lanes...). In parallel, in 2008-2009, the government had launched a six million euros package for the establishment of charging stations as part of a recovery plan (Figenbaum, 2016, page 23).

To achieve a larger scale deployment, i.e. all across the country, the government launched in 2011 an ambitious financial support program for fast charge stations (Figenbaum, 2016, Table 1, page16) for deploying a recharging station every $50 \mathrm{~km}$ on all major inter-city roads. The proceeds were allocated through a bidding process. At the same time recharging within cities was left to the market and stores such as Ikea, Mc Donald, etc. entered that business.

While the early stages of deployment had led to bankruptcies or withdrawals of electric car manufacturers from the market, in 2010 the car manufacturers launched a large variety of BEVs providing models with size and quality equivalent to traditional fossil fuel vehicles. In 2016, BEVs and Plug-in Hybrid Electric Vehicles (PHEVs) made more than half of new car 
sales in Norway ${ }^{12}$ and a gradual phasing out of incentives was contemplated (Figenbaum, 2016, page 25).

Compared to BEV, the current deployment of fuel cell electric vehicles (FCEV) remains at an infant stage. In France there are some demonstrations projects: for instance a limited number of hydrogen vehicles are deployed in the Normandy region through public fleets. Hydrogen retail stations (HRS) are heavily subsidized by EU and regional grants under a plan for 2016-2018 (Brunet and Ponssard, 2017). In Paris, in 2017, a private fleet of FCEV taxis is currently operating and it should reach 600 vehicles with around 10 HRS by $2020 .{ }^{13}$

In Germany a national deployment plan had been elaborated. To foster its achievement a national consortium was set up to provide funds with expectations to achieve as much as 400 HRS in 2023. ${ }^{14}$ The consortium involves the German state along with car manufacturers and fuel providers, i.e. hydrogen but also fossil fuels and electricity providers. ${ }^{15}$ However, German car manufacturers seem slow to market FCEVs, possibly because of a lack of direct financial stake in the consortium. ${ }^{16}$ In Japan a consortium had also been set up. In 2017, there were about a hundred HRS and 3000 FCEV. The objective of the consortium is to launch 80 more HRS for an expected car park of 40000 vehicles in 2021. Interestingly, the Japanese car manufacturers do have financial stakes in the consortium. ${ }^{17}$ In California, the California Air Resource Board has an explicit strategy of being technology neutral for promoting cars with low carbon emissions. Therefore, it regularly conducts open bids to attract HRS operators in different locations according to a predetermined regional plan. In 2017, there were about 50 HRS for about 5000 FCEV. ${ }^{18}$

This brief survey illustrates the significant involvement of the state and the variety of

\footnotetext{
${ }^{12}$ See https://www.weforum.org/agenda/2017/03/norway-is-leading-the-charge-towards-electric-vehiclesand-just-hit-another-milestone-along-the-way-d69a8170-cbdc-4d8a-95cd-f9bdf3c8e3ae/

${ }^{13}$ See http://www.caradisiac.com/les-taxis-hype-visent-les-600-vehicules-a-hydrogene-dici-a-2020-165007.htm

${ }^{14}$ See for instance http://www.eenewseurope.com/news/germany-plans-promoting-hydrogendrives-0.

${ }^{15}$ See Fuel Cells Bulletin 2013 (10) https://doi .org/10.1016/S1464-2859(13)70350-X

${ }^{16}$ Based on a private conversation with industry analysts

${ }^{17}$ See https://www.airliquide.com/fr/media/air-liquide-10-entreprises-japonaisesunissent-accelerer-deploiement-energie-hydrogene-japon

${ }^{18}$ See https://www.arb.ca.gov/msprog/zevprog/ab8/ab8_report_2017.pdf
} 
institutional set-ups put in place to by-pass the potential lock-in in the deployment. It also helps in positioning the insights our model can deliver, namely at the early phases of the expansion phase.

\subsection{The calibration of the model}

There are a number of prospective studies on the deployment of hydrogen or Fuel Cell Electric Vehicles (FCEV). Zachmann et al. (2012) revisit the economic rationale for public action for hydrogen vehicle emphasizing the role of public subsidies. Rösler et al. (2014) forecast that hydrogen vehicles could achieve a significant market share in Europe in 2050 (see also the more recent survey by KPMG, 2018). McKinsey \& Company (2010) gives an estimate of $15 \%$ market share for FCEV at the 2050 horizon for the German market. According to this scenario the number of FCEVs would increase from 95471 units in 2020 to more than 453452 units in 2025. In view of the preceding discussion this is far from realistic. Our calibration uses some of the cost figures from this study as revisited in Creti et al. (2018). It will deliver more credible values of fleet deployment. It is detailed in Table 1.

\begin{tabular}{c|c|c|c|c|c} 
Parameter & Unit & Take-off & Building-up & Expansion & Stationary \\
\hline $\mathrm{g}$ & $€ / \mathrm{yr}^{*} \mathrm{FCEV}^{2}$ & 0.005 & 0.005 & 0.005 & 0.000 \\
$c_{0}$ & $€ / \mathrm{yr}$ & 6000 & 6000 & 6000 & 5500 \\
$f$ & $€ / \mathrm{yr}$ & 50000 & 50000 & 50000 & 50000 \\
$\beta$ & $€ / \mathrm{yr}$ & 5000 & 5000 & 5000 & 5000 \\
$c_{F}$ & $€ * \mathrm{~S} / \mathrm{yr}^{*} \mathrm{FCEV}^{2}$ & 0.8 & 0.8 & 0.8 & 0.8 \\
$\mathrm{~b}$ & $€ / \mathrm{yr}^{*} \mathrm{FCEV}{ }^{2}$ & 0.2 & 0.2 & 0.2 & 0.2 \\
$\mathrm{a}$ & $€ / \mathrm{yr}^{*} \mathrm{FCEV}$ & 7000 & 8000 & 11000 & 11000
\end{tabular}

Table 1: Calibration of the model

We shall discuss four scenarios: a take-off phase, a building-up phase, an expansion phase and finally a stationary phase. For all scenarios the cost figures remain identical, except for the stationary phase where there is no longer any scale factor $(g=0)$ and, for consistency, the cost of a car is decreased from 6000 to $5500 € / y r$. For the demand function, the 
parameter $b$ is assumed to be constant while the parameter $a$, i.e. the willingness to pay, is increased reflecting the increased acceptability of consumers for FCEV as well as increases in the price of carbon.

The different scenarios will provide a sensitivity analysis. Indeed, a dynamic model would be more appropriate for an analysis covering a deployment scenario over time, with an increasing $\mathrm{CO}_{2}$ price, endogeneous entry and a decreasing scale effect. We shall come back to this question in the concluding section.

\subsection{The social optimum and the market equilibria}

From Table 1 we can derive the social optimum, the oligopoly equilibria for a given number $m$ of competing firms and the integrated monopoly equilibrium. The results are given in Table 2. Note that there is no market equilibrium for the take-off scenario. It can be seen that the integrated monopoly induces a larger number of refilling stations than the oligopoly equilibrium for the building-up scenario in spite of a lower number of cars. However the welfare loss is higher.

Without range anxiety $(\beta=0)$ the welfare loss due to the combination of imperfect competition and scale effects would be

$$
\frac{W^{*}(\beta=0)-W^{r}(\beta=0)}{W^{*}(\beta=0)}=\left(1-\frac{X^{E}}{X^{*}}\right)^{2}=\frac{1}{(m+1)^{2}}\left(1+m \frac{g}{b-g}\right)^{2}
$$

The losses reported in Table 2 are larger, the difference is due to range anxiety. A monopoly, with $b=0.2$ and $g=0.005$, would induce a loss of $26 \%$ for $\beta=0$, and a duopoly a loss of $12 \%$, to be compared with $100 \%$ in the take-off scenario and the $42.5 \%$ (integrated monopoly) and $36 \%$ (duopoly) in the building-up scenario. For a large willingness to pay, Proposition 1 is illustrated by the scenario stationary in which without imperfect competition nor scale effect the loss is only $0.3 \%$.

\subsection{The optimal subsidies for the various configurations}

The optimal subsidies corresponding to the various configurations are depicted Table 3. Consider first the optimal combined subsidies. Observe that the subsidy for infrastructure 


\begin{tabular}{|c|c|c|c|c|}
\hline Scenario & Take-off & Building-up & Expansion & Stationary \\
\hline \multicolumn{5}{|l|}{ Social optimum } \\
\hline $\mathrm{X}^{*}$ & 3293 & 8892 & 24796 & 26059 \\
\hline $\mathrm{K}^{*}$ & 20 & 39 & 86 & 90 \\
\hline Welfare $(\mathrm{M} € / \mathrm{yr})$ & .2 & 6.4 & 57.0 & 66.5 \\
\hline \multicolumn{5}{|c|}{ Oligopoly equilibrium } \\
\hline m (exogenous) & 1 & 2 & 10 & 10000 \\
\hline $\mathrm{X}^{r}$ & - & 4539 & 21610 & 25740 \\
\hline $\mathrm{K}^{r}$ & - & 13 & 61 & 73 \\
\hline Welfare loss (\%) & $100 \%$ & $36.1 \%$ & $2.0 \%$ & $.3 \%$ \\
\hline \multicolumn{5}{|c|}{ Integrated monopoly } \\
\hline $\mathrm{X}^{m}$ & - & 3455 & 11319 & 12292 \\
\hline $\mathrm{K}^{m}$ & - & 21 & 46 & 49 \\
\hline Welfare loss $(\%)$ & $100 \%$ & $42.3 \%$ & $30.2 \%$ & $28.4 \%$ \\
\hline
\end{tabular}

Table 2: The social optimum and the market equilibria 
is quite significant in percentage of the fixed cost of a refilling station. The range anxiety factor is quite expensive to internalize. Comparatively the subsidy for cars remains low, about 10 to $13 \%$ on the manufacturer price, which is an order of magnitude consistent with observations.

Let us now consider the other configurations. Firstly it is quite noticeable that for the take-off scenario subsidizing cars or infrastructure only would not be socially profitable: the induced market equilibrium with cars only would generate a negative welfare while with infrastructure only there is no equilibrium. This is not the case for the other scenarios. The welfare loss with respect to the first best (i.e. the combined policy ) appears to be higher for subsidizing infrastructure rather than cars (except for the stationary scenario in which there are no longer any market power nor scale effect). However the total subsidies would be much lower. In Table 3 we can see that the respective welfare return for investing $1 €$ with respect to the market equilibrium is much higher with infrastructure only. These figures provide a nice extension of Pavan et al. (2015) (see Lemma 4).

Secondly consider the integrated monopoly. For the take-off scenario it appears that the induced equilibrium would be socially profitable. Subsidizing cars while the monopoly internalizes the range anxiety would be a good policy. However this would be a very costly policy for the other scenarios as will be seen shortly.

\subsection{Analysis of the transfers induced by the policies}

The various subsidies have different redistribution impacts. In this partial equilibrium analysis we shall use the following identity (note that the industry profit for infrastrucure is null by construction):

$\Delta(\mathbf{W})=\Delta($ Consumer Surplus $)+\Delta($ Industry Profit for Cars $)-($ Total Subsidies $)$

We distinguish tax-payers from consumers composed of the limited segment of adopters of zero emission vehicles. We compute the variations for the different configurations using as a reference the values for the market equilibrium. For convenience the absolute values will be given for the combined subsidies while the ratio relative to this case will be given for the other configurations. All the results are detailed in Table 4. 


\begin{tabular}{|c|c|c|c|c|}
\hline Scenario & Take-off & Building-up & Expansion & Stationary \\
\hline \multicolumn{5}{|l|}{ Combined subsidies } \\
\hline$s_{K}(€ /$ station $)$ & 39574 & 29217 & 16758 & 16209 \\
\hline in percentage of $f$ & $79 \%$ & $58 \%$ & $34 \%$ & $32 \%$ \\
\hline$s_{V}(€ /$ car $)$ & 659 & 911 & 608 & 1 \\
\hline of which market power $\left((b-g) X^{*} / m\right)$ & 642 & 867 & 484 & 1 \\
\hline of which scale $\left(g X^{*}\right)$ & 16 & 44 & 124 & 0 \\
\hline Price rebate & $10 \%$ & $13 \%$ & $10 \%$ & $0 \%$ \\
\hline \multicolumn{5}{|l|}{ Integrated monopoly subsidies } \\
\hline$s_{V}(€ /$ car $)$ & 659 & 1778 & 4959 & 5212 \\
\hline \multicolumn{5}{|l|}{ Cars only subsidies } \\
\hline$s_{V}(€ /$ car $)$ & - & 1122 & 679 & 68 \\
\hline$X^{S B}$ & $(3775)$ & 9038 & 24827 & 26086 \\
\hline$K^{S B}$ & (11) & 26 & 70 & 74 \\
\hline Welfare loss wrt FB & $100 \%$ & $6.0 \%$ & $.3 \%$ & $.3 \%$ \\
\hline Welfare return of subsidies & - & $19.0 \%$ & $5.8 \%$ & $.7 \%$ \\
\hline \multicolumn{5}{|l|}{ Infrastructure only subsidies } \\
\hline$s_{K}(€ /$ car $)$ & - & 38791 & 22934 & 16216 \\
\hline$X^{S B}$ & - & 5894 & 22065 & 26056 \\
\hline$K^{S B}$ & - & 35 & 85 & 90 \\
\hline Welfare loss wrt FB & $100 \%$ & $13.7 \%$ & $1.3 \%$ & $.0 \%$ \\
\hline Welfare return of subsidies & - & $104 \%$ & $22 \%$ & $13 \%$ \\
\hline
\end{tabular}

Table 3: The optimal subsidies 
Consider first the policy associated to combined subsidies. Note that the total subsidy increases quite fast as one goes from the take-off scenario to the expansion scenario. The car rebate remains approximately constant while the size of the market increases. Subsidizing cars may become quite expensive for the tax payers. The corresponding subsidies go mostly into the pockets of the car adopters. Since this population may be quite affluent this may generate an important redistribution issue.

Consider now the other configurations. Subsidizing an integrated monopoly, while beneficial in the take-off scenario, explodes the bill for the tax payers for the only benefit of the industry profits. A policy to be used clearly only for take-off.

Finally consider policies in which either cars or infrastructure are subsidized. Interestingly, as far as industry profits and increased benefits for adopters are concerned, they can be seen as directly proportional to the policy with combined subsidies. ${ }^{19}$ As already noted infrastructure only is less costly but generates a lower increase in welfare.

\footnotetext{
${ }^{19}$ This is related to the quadratic specification, for which consumer net surplus is $b X^{2} / 2$, and with Cournot competition the car industry profit is $(b-g) X^{2} / m$ (using the first order condition 40 ).
} 


\begin{tabular}{|c|c|c|c|c|}
\hline Scenario & Take-off & Building-up & Expansion & Stationary \\
\hline \multicolumn{5}{|c|}{ Combined subsidies (M€/yr) } \\
\hline Tax payers & -3.0 & -9.2 & -16.5 & -1.5 \\
\hline Increase in profit & 2.1 & 5.7 & 2.9 & 0. \\
\hline Increase for adopters & 1.1 & 5.85 & 14.78 & 1.65 \\
\hline Increase of welfare & .2 & 2.3 & 1.16 & .18 \\
\hline \multicolumn{5}{|c|}{$\begin{array}{l}\text { Integrated monopoly } \\
\text { (ratio wrt combined subsidies) }\end{array}$} \\
\hline Tax payers & .73 & 1.71 & 7.45 & 92.59 \\
\hline Increase in profit & .62 & 2.15 & 37.93 & 406673 \\
\hline Increase for adopters & 1 & 1 & 1 & 1 \\
\hline Increase of welfare & 1 & 1 & 1 & 1 \\
\hline \multicolumn{5}{|c|}{$\begin{array}{l}\text { Cars only } \\
\text { (ratio wrt combined subsidies) }\end{array}$} \\
\hline Tax payers & - & 1.10 & 1.02 & 1.21 \\
\hline Increase in profit & - & 1.04 & 1.01 & 1.09 \\
\hline Increase for adopters & - & 1.04 & 1.01 & 1.09 \\
\hline Increase of welfare & - & .84 & .85 & .06 \\
\hline \multicolumn{5}{|c|}{$\begin{array}{l}\text { Infrastructure only } \\
\text { (ratio wrt combined subsidies) }\end{array}$} \\
\hline Tax payers & - & .15 & .12 & .99 \\
\hline Increase in profit & - & .24 & .13 & .99 \\
\hline Increase for adopters & - & .24 & .13 & .99 \\
\hline Increase of welfare & - & .62 & .37 & 1.0 \\
\hline
\end{tabular}

Table 4: The analysis of transfers

\subsection{The benefit of combining local and global policies}

So far we have implicitly considered one closed country. As a matter of fact, the two phenomena of range anxiety and scale effects take place within different spatial scales. Consumers 
travel within local areas, towns or regions. Car manufacturers are international companies that supply vehicles worldwide. ${ }^{20}$ Range anxiety is a local phenomemon and scale effect a global one. In this section a simple extension of the model is used to explicitly explore this remark.

Consider two identical countries (with the same parameter values), and two extreme cases: Autarky and Global. Autarky corresponds to the analysis conducted so far, each country is in isolation with $m$ national car manufacturers and local scale effects. In Global, the $2 \times m$ car manufacturers sell in the two countries and scale effects are global. In all cases considered the same quantities of cars and stations are sold and built in both countries, the quantity of cars in an individual country is denoted $X$ and the quantity of stations $K$.

The scenario Global is obtained with a simple change of parameter values. For the social optimum, the two countries coordinate and maximize joint welfare. The optimal quantities of $X$ and $K$ (these are national quantities) are equal to the optimal quantities with a single country and a scale parameter $2 g$. For the market equilibrium, $2 m$ manufacturers are competing on each market, and the equilibrium quantity of cars on each market is given by equation (16) replacing $g$ by $2 g$ and $m$ by $2 m$. The subsidies are derived accordingly. ${ }^{21}$ Altogether we get Table 5. The comparison is done only for scenario building-up.

The benefit of going from Autarky to Global is quite spectacular. The welfare gain for each country is $6.6 \%$ (from 6.4 to $6.8 \mathrm{M} € / \mathrm{yr}$ ) while the total subsidies is reduced by $33 \%$ (from 9.2 to $6.2 \mathrm{M} € / \mathrm{yr}$ )! These benefits are due to the increase of the scale effect and the number of competitors.

It would be worth pursuing the analysis in a more general setting with non identical countries. The gains from international trade might then be unequally distributed. If asymmetry with respect to production costs were introduced, the impact of international competition on the survival of inefficient firms would introduce industrial policy considerations.

\footnotetext{
${ }^{20}$ Figenbaum (2016) describes the role of foreign car manufacturers at the different stages of the deployment of BEV in Norway.

${ }^{21}$ An equivalent way to obtain Global is to consider total quantities $X_{G}$ and $K_{G}$ instead of national ones. The world quantities are equal to the single country ones with a double market size ( $b$ is replaced by $2 b)$, a doubled range anxiety $(\beta$ replaced by $2 \beta$ ) and twice as many competitors ( $m$ replaced by $2 m$ ).
} 


\begin{tabular}{l|cc}
\hline Scenario building-up & Autarky & Global \\
\hline \hline Social optimum & & \\
\hline$X^{*}$ & 8892 & 9397 \\
$K^{*}$ & 39 & 41 \\
Welfare (M€/yr) & 6.4 & 6.8 \\
\hline \hline Market equilibrium & & \\
\hline m (exogenous) & 2 & 4 \\
$\mathrm{X}^{r}$ & 4539 & 5987 \\
$\mathrm{~K}^{r}$ & 13 & 17 \\
Welfare loss & $36 \%$ & $22 \%$ \\
\hline \hline Optimal policy & \multicolumn{2}{|c}{} \\
\hline$s_{K}(€ /$ station) & 29217 & 28577 \\
$s_{V}(€ /$ car $)$ & 911 & 539 \\
Total subsidies per country $(\mathrm{M} € / \mathrm{yr})$ & 9.2 & 6.2 \\
\hline
\end{tabular}

Table 5: The benefit of going from Autarky to Global

\section{Conclusion}

In this paper we formalize the interaction between three market failures in the deployment of zero emission vehicles: indirect network effects, scale effects, which incorporate learningby-doing and spillovers, and imperfect competition among car producers. Indirect network effects come from the deployment of filling stations, and are associated to a market failure because of an unpriced benefit for consumers from filling stations. The more stations there are the lower the cost to search and reach a station.

Ordinarily there are three local social extrema (two maxima and a minimum) and three market equilibria, so that there is a possibility of lock-in and a tipping point exists. We then focus on the Pareto dominating equilibrium and derive the optimal subsidies to achieve the social optimum through market forces. We also examine two other schemes: one in which an integrated monopoly jointly operates the infrastructure and the manufacturing of 
cars, another one in which only car rebates or infrastructure subsidies would be used. This analysis points out the superiority of jointly subsidizing the capital cost of infrastructure and reducing car prices through rebates. Indeed, allowing only either for car rebates or infrastructure subsidies would not permit to achieve the social optimum and be particularly detrimental in the early phase of deployment. Allowing for an integrated monopoly can only be justified at the very early phase of deployment since competition in the car market is a key factor for the expansion phase of the deployment.

Our model is a static one and has the advantage of providing analytical solutions. In this respect it is a useful complement to larger complex models such as Harrison and Thiel (2017), in which it is difficult to disentangle the effects of numerous hypotheses. For instance our model allows to evaluate the relative importance of the market failures at the various stages of deployment. Our model also provides a natural step to build more elaborate analytical models, in particular dynamic ones. Indeed a dynamic model would be appropriate to analyze the yearly feedbacks of fleet emission regulations for car manufacturers combined with quantitative targets expressed in $\mathrm{CO}_{2}$ reduction for the transport sector. We do not model entry of car manufacturers, which should be endogenously driven. This point is important since the degree of competition appears as a crucial factor of success. Ideally, the interaction between the various technologies such as BEV and FCEV, as well as specific or technology neutral policies, should also be considered.

We illustrate our model with a numerical exercise based on the deployment of hydrogen cars. According to our calibration we find that a subsidy of approximately $80 \%$ of the fixed capital cost of a hydrogen retailing station and a rebate of approximately $10 \%$ on the listed price of cars in the take-off stage would be necessary to induce the social optimum through market forces. The level of the infrastructure subsidy would gradually decline as long as the market develops. The car rebates depends on two factors: the degree of competition and the scale effect. We also showed that a joint venture between fuel providers and car manufacturers, as it has been implemented in Germany and Japan, has some short term advantage for optimizing the network as long as the long-term discipline of competition remains in place for cars. Finally a simple extension is provided to enhance the benefit of coordinating national policies: while network effects are mostly regional, scale effect and 
market power can be strongly mitigated by allowing international trade. An important issue is left out in our empirical analysis, it concerns the uncertainty of the deployment and the influence it may have on the optimal level of subsidy. Indeed commitments are necessary for investing in the infrastructure and this may require a detailed treatment using option theory. This is left for future research.

This model seeks to bridge the gap between conceptual analysis and discussions of scenarios issued from complex numerical models. We think that this approach could be applied to other forms of green transportation: buses, trucks, autonomous vehicles... and possibly to start-ups deployments (startups incubators) or rehabilitation of town centers, all of which benefit of pooling resources, so as to highlight the interaction between indirect local network effect and more global scale effect.

\section{References}

Arthur, W. B. (1989). Competing technologies, increasing returns, and lock-in by historical events, The economic journal 99(394): 116-131.

Bjerkan, K. Y., Nørbech, T. E. and Nordtømme, M. E. (2016). Incentives for promoting battery electric vehicle (bev) adoption in norway, Transportation Research Part D: Transport and Environment 43: 169-180.

Brand, C., Anable, J. and Tran, M. (2013). Accelerating the transformation to a low carbon passenger transport system: The role of car purchase taxes, feebates, road taxes and scrappage incentives in the uk, Transportation Research Part A: Policy and Practice 49: 132-148.

Brécard, D. (2013). Environmental quality competition and taxation in the presence of green network effect among consumers, Environmental and Resource Economics 54(1): 1-19.

Brunet, J. and Ponssard, J.-P. (2017). Policies and deployment for fuel cell electric vehicles an assessment of the normandy project, International Journal of Hydrogen Energy 42(7): 4276-4284. 
Chou, C.-f. and Shy, O. (1990). Network effects without network externalities, International Journal of Industrial Organization 8(2): 259-270.

Church, J., Gandal, N. and Krause, D. (2008). Indirect network effects and adoption externalities, Review of Network Economics 7(3).

Clements, M. T. (2004). Direct and indirect network effects: are they equivalent?, International Journal of Industrial Organization 22(5): 633-645.

Corchón, L. C. (2008). Welfare losses under cournot competition, International Journal of Industrial Organization 26(5): 1120-1131.

Creti, A., Kotelnikovaa, A., Meunier, G. and Ponssard, J.-P. (2018). Defining the abatement cost in presence of learning-by-doing: Application to the fuel cell electric vehicle., Environmental and Resources Economics (forthcoming).

Diamond, D. (2009). The impact of government incentives for hybrid-electric vehicles: Evidence from us states, Energy Policy 37(3): 972-983.

Figenbaum, E. (2016). Perspectives on norway's supercharged electric vehicle policy, Environmental Innovation and Societal Transitions .

Geels, F. W. (2002). Technological transitions as evolutionary reconfiguration processes: a multi-level perspective and a case-study, Research policy 31(8-9): 1257-1274.

Geels, F. W. (2012). A socio-technical analysis of low-carbon transitions: introducing the multi-level perspective into transport studies, Journal of transport geography 24: 471-482.

Greaker, M. and Heggedal, T.-R. (2010). Lock-in and the transition to hydrogen cars: should governments intervene?, The BE Journal of Economic Analysis $\&$ Policy 10(1).

Greaker, M. and Midttømme, K. (2016). Network effects and environmental externalities: Do clean technologies suffer from excess inertia?, Journal of Public Economics 143: 27-38.

Harrison, G. and Thiel, C. (2017). An exploratory policy analysis of electric vehicle sales competition and sensitivity to infrastructure in europe, Technological Forecasting and Social Change 114: 165-178. 
Hidrue, M. K., Parsons, G. R., Kempton, W. and Gardner, M. P. (2011). Willingness to pay for electric vehicles and their attributes, Resource and Energy Economics 33(3): 686-705.

IEA (2013). World Energy Outlook.

URL: https://www.iea.org/publications/freepublications/publication/WEO2013.pdf

IEA (2017). Global EV outlook 2017. Two million and counting.

URL: https://www.iea.org/publications/freepublications/publication/GlobalEVOutlook2017.pdf

Kline, D. (2001). Positive feedback, lock-in, and environmental policy, Policy Sciences 34(1): 95-107.

KPMG (2018). Global Automotive Executive Survey, KPMG international.

URL: https://gaes.kpmg.de/

Lévay, P. Z., Drossinos, Y. and Thiel, C. (2017). The effect of fiscal incentives on market penetration of electric vehicles: A pairwise comparison of total cost of ownership, Energy Policy 105: 524-533.

Liebowitz, S. J. and Margolis, S. E. (1995). Are network externalities a new source of market failure?, Research in Law and Economics 17(0): 1-22.

McKinsey \& Company, A. (2010). Portfolio of powertrains for europe: a fact-based analysis.

Meyer, P. E. and Winebrake, J. J. (2009). Modeling technology diffusion of complementary goods: The case of hydrogen vehicles and refueling infrastructure, Technovation 29(2): 7791.

Nyborg, K., Anderies, J. M., Dannenberg, A., Lindahl, T., Schill, C., Schlüter, M., Adger, W. N., Arrow, K. J., Barrett, S., Carpenter, S. et al. (2016). Social norms as solutions, Science 354(6308): 42-43.

OECD (2014). The Economic Consequences of Outdoor Air Pollution.

URL: $\quad h t t p: / / w w w . o e c d . o r g / e n v / t h e-e c o n o m i c-c o n s e q u e n c e s-o f-o u t d o o r-a i r-p o l l u t i o n-$ 9789264257474-en.htm 
Pavan, G. et al. (2015). Green car adoption and the supply of alternative fuels, Technical report, Working paper.

Rösler, H., van der Zwaan, B., Keppo, I. and Bruggink, J. (2014). Electricity versus hydrogen for passenger cars under stringent climate change control, Sustainable Energy Technologies and Assessments 5: 106-118.

Salop, S. C. (1979). Monopolistic competition with outside goods, The Bell Journal of Economics pp. 141-156.

Sartzetakis, E. S. and Tsigaris, P. (2005). Environmental externalities in the presence of network effects: Adoption of low emission technologies in the automobile market, Journal of Regulatory Economics 28(3): 309-326.

Shy, O. (2011). A short survey of network economics, Review of Industrial Organization 38(2): 119-149.

Zachmann, G., Holtermann, M., Radeke, J., Tam, M., Huberty, M., Naumenko, D. and Faye, A. N. (2012). The great transformation: decarbonising Europe's energy and transport systems., Bruegel Blueprint 16.

\section{Appendix}

\section{A Optimum}

Derivatives are denoted with indices. Derivatives of welfare are:

$$
\begin{aligned}
W_{X} & =a-b X-\frac{\beta}{K}-\left(c_{0}-2 g X\right)-c_{F} \frac{X}{K} \\
& =\left[a-c_{0}-\frac{\beta}{K}\right]-\left[b-2 g+\frac{c_{F}}{K}\right] X \\
W_{K} & =\frac{\beta X}{K^{2}}+\frac{c_{F}}{2} \frac{X^{2}}{K^{2}}-f=\frac{1}{K^{2}}\left[\beta X+\frac{c_{F}}{2} X^{2}\right]-f
\end{aligned}
$$

Second order derivatives are:

$$
W_{X X}=-\left(b-2 g+\frac{c_{F}}{K}\right) ; W_{K K}=-\frac{2}{K^{3}}\left[\beta X+\frac{c_{F}}{2} X^{2}\right] ; W_{X K}=\frac{1}{K^{2}}\left(\beta+c_{F} X\right)
$$


So $W_{X X}>0$ and $W_{K K}<0$, the Hessian is denoted $H$ :

$$
H=W_{X X} W_{K K}-W_{X K}^{2}=\frac{1}{K^{3}}\left[(b-2 g)\left(2 \beta+c_{F} X\right) X-\frac{\beta^{2}}{K}\right] .
$$

\section{A.1 Proof Proposition 1}

Couple of equations satisfied at the optimal allocation

$$
W_{X}=0 \text { and } W_{K}=0
$$

For $\beta=0$ the solutions are $(0,0)$ and the one given by equation (9), the first is a local minimum, the second the unique local maximum, and thus the global maximum.

Result 1: For small $\beta$ the optimum is positive: $\left(X^{*}, K^{*}\right) \in \mathbb{R}_{>0}^{2}$.

Proof. By continuity: $W\left(X^{*}(\beta=0), K^{*}(\beta=0), \beta=0\right)>0$ so that for small $\beta, W\left(X^{*}(\beta=\right.$ $\left.0), K^{*}(\beta=0), \beta\right)>0=W(0,0, \beta)$.

Define $K^{0}(X)$ as in equation $(7)$ and $K^{1}(X)$ the inverse of $X^{0}(K)$ given by eq. 8:

$$
K^{1}(X)=\frac{\beta+c_{F} X}{\left(a-c_{0}\right)-(b-2 g) X}
$$

It is well define for $X<\left(a-c_{0}\right) /(b-2 g)={ }_{\text {def }} \bar{X}$. These functions are such that $W_{X}\left(X, K^{1}(X)\right)=$ 0 and $W_{K}\left(X, K^{0}(K)\right)=0$.

Result 2: Two situations can arise: either for all $X \in(0, \bar{X}) K^{1}(X)>K^{0}(X)$ or there are two solutions $X_{-}<X_{+}$to the equation $K^{1}(X)=K^{0}(X)$.

\section{Proof.}

- $K^{1}(0)>K^{0}(0)$ and $K^{1}(X)>K^{0}(X)$ for $X$ sufficiently close to $\bar{X}$.

- The derivatives of $K^{1}$ and $K^{0}$ are:

$$
\begin{gathered}
K^{0 \prime}=\frac{1}{2 \sqrt{f}} \frac{\beta+c_{F} X}{\sqrt{\beta X+c_{F} X^{2} / 2}} \text { and } K^{1 \prime}=\frac{c_{F}\left(a-c_{0}\right)+(b-2 g) \beta}{\left[\left(a-c_{0}\right)-(b-2 g) X\right]^{2}} \\
K^{0 \prime \prime}=-\frac{\beta^{2}}{4 \sqrt{f}}\left[\beta X+\frac{c_{F}}{2} X^{2}\right]^{-3 / 2} \text { and } K^{1 \prime \prime}=2(b-2 g) \frac{c_{F}\left(a-c_{0}\right)+(b-2 g) \beta}{\left[\left(a-c_{0}\right)-(b-2 g) X\right]^{3}}
\end{gathered}
$$

The difference $K^{1}(X)-K^{0}(X)$ is convex. Its derivative is increasing, first negative (since $\left.K^{0 \prime}(0)=+\infty\right)$ and eventually positive (since $K^{1 \prime}(\bar{X})=+\infty$ ). Therefore, either $K^{1}-K^{0}>0 \forall X \in(0, \bar{X})$, or there are two roots $X_{-}$and $X_{+}$to the equation $K^{1}=K^{0}$ with $0<X_{-} \leq X_{+}<\bar{X}$. 
Each root $X_{ \pm}$cancels the derivative of the function $W\left(X, K^{0}(X)\right)$ and is a local extremum (and associated with a singular point of $W(X, K)$. At the lowest root, $K^{1}-K^{0}$ is decreasing so that $W_{X X} W_{K K}<W_{X K}^{2}$ and $X_{-}$is a local minimum of $W\left(X, K^{0}(X)\right)$ (and $\left(X_{-}, K 0\left(X_{-}\right)\right.$) a saddle point of $W(X, K))$. At $X_{+}$, the function is increasing $W_{X X} W_{K K}>W_{X K}^{2}$ and $X_{+}$ is a local maximum.

Combine Results 1 and 2 to get that for small $\beta$ there are two local maxima (one at $(0,0)$ the other positive) and a local minimum. For large $\beta$ there is a unique maximum at $(0,0)$.

When there are two local maxima, the positive local maximum is the global maximum if and only if $\beta$ is sufficiently small, otherwise the maximum is at $(0,0)$.

\section{Impact of $\beta$ :}

In matrix form:

$$
\left[\begin{array}{ll}
W_{X X} & W_{X K} \\
W_{X K} & W_{K K}
\end{array}\right]\left[\begin{array}{c}
X_{\beta} \\
K_{\beta}
\end{array}\right]=\left[\begin{array}{c}
-W_{X \beta} \\
-W_{K \beta}
\end{array}\right]
$$

therefore, with $H$ define by eq. (32):

$$
\left[\begin{array}{c}
X_{\beta} \\
K_{\beta}
\end{array}\right]=\frac{1}{H}\left[\begin{array}{c}
-W_{K K} W_{X \beta}+W_{X K} W_{K \beta} \\
-W_{X X} W_{K \beta}+W_{X K} W_{X \beta}
\end{array}\right]=\frac{1}{H}\left[\begin{array}{c}
-\beta X^{*} / K^{* 4} \\
\left(X^{*}(b-2 g)-\beta / K^{*}\right) / K^{* 2}
\end{array}\right]
$$

So $X$ is strictly decreasing with respect to $\beta$. And the quantity of stations per vehicle is

$$
\frac{K^{*}}{X^{*}}=\left[\frac{1}{f}\left(\frac{c_{F}}{2}+\frac{\beta}{X^{*}}\right)\right]^{1 / 2}
$$

which is strictly increasing with respect to $\beta$ since $X^{*}(\beta)$ is decreasing.

\section{A.2 Proof of Corollary 1}

\section{Impact of $a$}

Welfare at the positive local maximum is increasing with respect to $a$, so the positive local maximum is the global maximum for large $a$.

Again, using the matrix form, the derivatives of optimum quantities with respect to $a$ are:

$$
\left[\begin{array}{c}
X_{a}^{*} \\
K_{a}^{*}
\end{array}\right]=\frac{1}{H}\left[\begin{array}{c}
-W_{K K} \\
W_{X K}
\end{array}\right]=\frac{1}{H}\left[\begin{array}{c}
2\left(\beta X^{*}+\frac{c_{F}}{2} X^{* 2}\right) / K^{* 3} \\
\left(\beta+c_{F} X^{*}\right) / K^{* 2}
\end{array}\right]=\frac{1}{H}\left[\begin{array}{c}
2 f / K^{*} \\
\left(\beta+c_{F} X^{*}\right) / K^{* 2}
\end{array}\right]
$$


And at the optimum the Hessian is:

$$
H=\frac{1}{K^{* 3}}\left[2(b-2 g)\left(\beta X^{*}+\frac{c_{F}}{2} X^{* 2}\right)-\frac{\beta^{2}}{K^{*}}\right]=\frac{1}{K^{* 3}}\left[2(b-2 g) f K^{2}-\frac{\beta^{2}}{K^{*}}\right]
$$

so that

$$
X_{a}^{*}=\frac{1}{b-2 g} \frac{2 f K^{* 2}}{2 f K^{* 2}-\beta^{2} / K^{*}}>\frac{1}{b-2 g}
$$

Remark: the denominator is positive because the Hessian is at a maximum.

Both quantities are strictly increasing with respect to $a$ at a bounded rate, they converge toward $+\infty$. For sufficiently large "a" $X^{*}>c_{0} / g$, assumption A1 is no longer satisfied, and the situation is then equivalent to $c_{0}=g=0$ (thanks to learning by doing production cost are null).

Remark: there is a range of $a$ at which $X^{*}=c_{0} / g$ but we do not analyze these peculiar situations in detail.

Let us consider that $c_{0}=g=0$ (the same formula hold for the derivative with respect to $a$ ). Both $K^{*}$ and $X^{*}$ converge towards $+\infty$, and $X^{*} / K^{*}$ increases and converges towards $x_{m}$ (from equation (7)).

And for the convergence of welfare ratio, note first that from the first order condition $W_{X}=0$, the ratio $b X^{*} /\left(a-\bar{C}_{F}\right)$ converges toward 1 , and then write:

$$
\begin{aligned}
& W\left(X, K^{0}(X)\right)=\left(a-\bar{C}_{F}-\frac{b}{2} X\right) X+X\left[\bar{C}_{F}-\frac{\beta}{K}-\frac{c_{F}}{2} \frac{X}{K}-f \frac{K}{X}\right] \\
& \frac{W\left(X, K^{0}(X)\right)}{\left(a-\bar{C}_{F}\right)^{2} /(2 b)}=1-\left(\frac{b X}{a-\bar{C}_{F}}-1\right)^{2}+\frac{2 b X}{\left(a-\bar{C}_{F}\right)^{2}}\left[\bar{C}_{F}-\frac{\beta}{K}-\frac{c_{F}}{2} \frac{X}{K}-f \frac{K}{X}\right]
\end{aligned}
$$

the last two terms converge towards zero when $a$ increases.

\section{B Equilibrium}

\section{B.1 Proof of Lemma 2}

For a given fuel price $p_{F}$, the game is a standard linear Cournot game. Each producer maximizes its profit given by eq. 4.2 yielding the first order condition:

$$
\left[a-b(x+y)-\frac{\beta}{K}-p_{F}\right]-b x-\left(c_{0}-g(x+y)\right)+g x=0
$$


So that the aggregate quantity produced $X^{r}$ is the solution of

$$
a-c_{0}-\frac{\beta}{K}-p_{F}-\frac{m+1}{m}(b-g) X^{r}=0
$$

so that

$$
X^{r}=\frac{m}{m+1} \frac{1}{b-g}\left[a-c_{0}-\frac{\beta}{K}-p_{F}\right]
$$

if positive. And at the equilibrium, the price of fuel is $p_{F}=c_{F} X / K$, injecting in the above expression gives equation (14).

\section{B.2 Proof of Proposition 2}

There is always an equilibrium at $X=0, K=0$.

If an equilibrium with positive quantities exists it is such that

$$
X=\frac{m}{m+1} \frac{1}{b-g}\left[a-c_{0}-\frac{\beta}{K}-p_{F}\right] \text { and } p_{F}=c_{F} \frac{X}{K}, K=\frac{X}{x_{m}}
$$

so that $X^{E}$ is the solution of a second order equation:

$$
\frac{m+1}{m}(b-g) X^{2}-\left(a-c_{0}-\bar{C}_{F}\right) X-\beta x_{m}=0
$$

the analysis of which gives the result of Proposition: there is no real solution if condition (15) is satisfied and otherwise the two solutions are given by equation (16).

\section{Proof of Proposition 6 and Lemmas 3 and}

Let us write $K^{r}$ and $X^{r}$ as functions of the subsidies: $K^{r}\left(X, s_{K}\right)$ and $X^{r}\left(K, s_{V}\right)$. Note that each function has only one subsidy as argument. The influence of $s_{K}$ on $X$ only occurs indirectly. The two reaction functions are given by:

- $K^{r}\left(X, s_{K}\right)$ solves

$$
C_{F}^{\prime} \times \frac{X}{K}-C_{F}\left(\frac{X}{K}\right)=\left(f-s_{K}\right)
$$

it is $K^{r}\left(X, s_{K}\right)=X / \sqrt{2\left(f-s_{K}\right) / c_{F}}$ 
- $X^{r}\left(K, s_{V}\right)$ is such that

$$
\left[(a-b X)-\frac{\beta}{K}\right]+s_{V}-\frac{b-g}{m} X=\left[c_{0}-g X\right]+c_{F} \frac{X}{K}
$$

that is

$$
X^{r}=\frac{m}{(m+1)(b-g)}\left[a+s_{V}-c_{0}-\frac{\beta}{K}-p_{F}\right]=\frac{a+s_{V}-c_{0}-\frac{\beta}{K}}{\frac{m+1}{m}(b-g)+c_{F} / K}
$$

Equilibrium quantities, at the stable non-null equilibrium, are denoted $K^{E}\left(s_{K}, s_{V}\right)$ and $X^{E}\left(s_{K}, s_{V}\right)$, and depends on both subsidies.

\section{C.1 Proof of Proposition 4 and Proposition 5}

It is straightforward to verify that the two equilibrium conditions (39) and (40) with the expressions of $s_{K}$ and $s_{V}$ given by equations (19) and (18) coincide with the couple of equations satisfied by the optimal couple $\left(X^{*}, K^{*}\right)$.

\section{C.2 Proof of Proposition 6}

To find the optimal subsidy $s_{V}$ one can either take the derivative of $W\left(X^{E}\left(0, s_{V}\right), K^{E}\left(0, s_{V}\right)\right)$ with respect to $s_{V}$ or the derivative of $W\left(X, K^{r}(X, 0)\right)$ with respect to $X$ since $s_{V}$ influences $K^{E}$ only indirectly.

Taking the derivative of welfare gives eq. (25) and injecting equation (40) and $K=X / x_{m}$ gives

$$
\frac{d W}{d X}=\left(\frac{b}{m}+\frac{(m-1) g}{m}\right) X-s_{V}+\frac{\beta x_{m}}{X}
$$

the expression of the subsidy in Proposition 6 follows.

Then, from equation (25), the two $\beta / K$ terms cancel injecting $K=X / x_{m}$ and $C_{F}^{\prime}\left(X / K^{r}\right)=$ $C_{F}^{\prime}\left(x_{m}\right)=\bar{C}_{F}$ gives the expression $(26)$.

\section{C.3 proof of Lemma 3}

The optimal subsidy $s_{K}$ is found by looking at the derivatives of $W\left(X^{r}(K, 0), K\right)$. 


$$
\begin{aligned}
\frac{d W}{d K} & =\left[\frac{b}{m}+g \frac{m-1}{m}\right] X^{r}(K) \frac{\partial X^{r}}{\partial K}+\left[\frac{\beta X}{K^{2}}-s_{K}\right] \text { from (39) and (??) } \\
& =\left[\frac{b}{m}+g \frac{m-1}{m}\right] X^{r}(K) \frac{\beta+c_{F} X^{r}}{\frac{m+1}{m}(b-g)+c_{F} / K}+\frac{\beta X}{K^{2}}-s_{K}
\end{aligned}
$$

\section{C.4 Proof of Lemma 4}

Let us consider that the regulator has $\epsilon$ euros.

- If a subsidy on stations is fixed it should be such that $s_{K} K^{E}\left(s_{K}, 0\right)=\epsilon$ so that for a small $\epsilon, d s_{K}=1 / K^{E}(0,0)$.

At the equilibrium $X^{E}=X^{r}\left(K^{E}, 0\right)$ and $K^{E}=K^{r}\left(X^{E}, s_{K}\right)$ so that

$$
d X=\frac{1}{K^{E}} \frac{\partial X^{E}}{\partial s_{K}}=\frac{1}{K^{E}} \frac{\partial X^{r}}{\partial K} \frac{\partial K^{E}}{\partial s_{K}}=\frac{\partial X^{r}}{\partial K}\left(1-\frac{\partial X^{r}}{\partial K} \frac{\partial K^{r}}{\partial X}\right)^{-1} \frac{\partial K^{r}}{\partial s_{k}} \frac{1}{K^{E}}
$$

- Similarly, for a subsidy on vehicles such that $s_{V} X^{E}=\epsilon$ the change of $X$ is:

$$
d X=\left(1-\frac{\partial X^{r}}{\partial K} \frac{\partial K^{r}}{\partial X}\right)^{-1} \frac{\partial X^{r}}{\partial s_{V}} \frac{1}{X}
$$

- Then the difference on the total quantity of vehicles if $\epsilon$ is spent to subsidize stations or to subsidize vehicles is:

$$
\left[\frac{\partial X^{r}}{\partial K} \frac{\partial K^{r}}{\partial s_{k}} \frac{1}{K^{E}}-\frac{\partial X^{r}}{\partial s_{V}} \frac{1}{X^{E}}\right]\left(1-\frac{\partial X^{r}}{\partial K} \frac{\partial K^{r}}{\partial X}\right)^{-1}
$$

and the first bracketed factor is equal to, denoting $D=\frac{m+1}{m}(b-g)+c_{F} / K$ the denominateur in the expression (41) of $X^{r}$.

$$
\frac{1}{D}\left[\frac{\beta}{K^{2}}+c_{F} \frac{X}{K^{2}}\right]\left[\frac{1}{c_{F}} \frac{K^{3}}{X^{2}}\right] \frac{1}{K}-\frac{1}{D} \frac{1}{X}=\frac{1}{D} \frac{1}{X^{3}} \frac{\beta}{c_{F}}
$$

